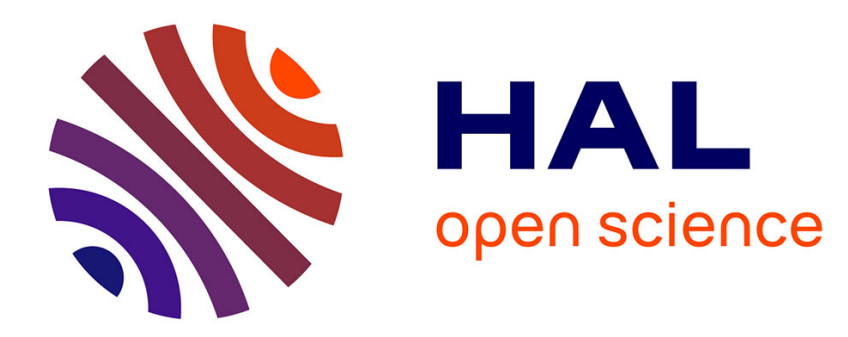

\title{
Dynamic tensile testing of sheet metal
}

P. Mouro, Gérard Gary, Han Zhao

\section{- To cite this version:}

P. Mouro, Gérard Gary, Han Zhao. Dynamic tensile testing of sheet metal. Journal de Physique IV Proceedings, 2000, 10, pp.149-153. 10.1051/jp4:2000925 . hal-00111309

\section{HAL Id: hal-00111309 \\ https://hal.science/hal-00111309}

Submitted on 22 Jun 2018

HAL is a multi-disciplinary open access archive for the deposit and dissemination of scientific research documents, whether they are published or not. The documents may come from teaching and research institutions in France or abroad, or from public or private research centers.
L'archive ouverte pluridisciplinaire HAL, est destinée au dépôt et à la diffusion de documents scientifiques de niveau recherche, publiés ou non, émanant des établissements d'enseignement et de recherche français ou étrangers, des laboratoires publics ou privés. 


\title{
Dynamic tensile testing of sheet metal
}

\author{
P. Mouro, G. Gary* and H. Zhao**
}

\author{
PSA, Peugeot-Citroën, Direction of Research and Innovation, chemin de la Malmaison, \\ 91570 Bièvres, France \\ " Laboratoire de Mécanique des Solides, École Polytechnique, 91128 Palaiseau cedex, France \\ ** Laboratoire de Mécanique et Technologie - Cachan, Université Pierre et Marie Curie Paris 6, \\ 61 avenue du Président Wilson, 94235 Cachan cedex, France
}

\begin{abstract}
The testing of sheet metal at high strain rates requires the use of the SHPB set-up. This technique provides satisfactory results as far as the compression and shear are concerned. A modified SHPB set-up is presented here, which extends the scope of this technique to the tensile loading of sheet metals. In this case, many measurement problems arise due to the way in which the specimen is connected to the bars, which never completely prevents unexpected slipping and is liable to induce interference waves due to an impedance mismatch. The technique described here was based on the "hat specimen" technique proposed by Lindholm [1]. A two-dimensional "hat shaped" specimen is subjected to compression loading. A tensile state is induced in a symmetrically necked area, where higher strains are concentrated. Connecting supports of an appropriate shape are attached to the bars. They have the same impedance as that of the bars to avoid the occurrence of any interference waves. The "hat" shape prevents sliding, and to ensure perfect initial contact conditions, the complete system is elastically pre-stressed. A special method of wave analysis is then used to determine the forces and displacements occurring at the specimen ends from the strain signals recorded in the bars.
\end{abstract}

\section{INTRODUCTION}

The numerical modelling of crash tests is nowadays widely used in the automotive industry. It requires the use of a reliable constitutive model which can be used with large strains (up to 30\%) and large strain rates in the range of $1 / \mathrm{s}$ to $1000 / \mathrm{s}$. The corresponding tests at low strain rates are usually performed under tension loading, using a classical hydraulic testing machine. Tests at high strain rates are performed under compression loading with the Split Hopkinson Pressure Bar. The complete range of strain-rates obtained so far suggests that the behaviour of metal sheets has always been implicitly assumed to be symmetric between traction and compression.

To avoid making this assumption, it was necessary to perform accurate tests under both tension and compression at the same average strain rates. For this purpose, we extended the SHPB technique to tension testing, as it yields accurate results in the high strain-rate range. This approach is in line with that used with the study by Quik and al [2], and the present paper deals with a new SHPB device that can be used extensively for the tensile testing of industrial metal sheets.

Dynamic tensile testing using SHPB is a rather old topic in the case of cylindrical specimens that can be connected directly to the bars [3]. Nicholas [4] loaded the incident bar with a compressive wave that was trapped in a collar surrounding the specimen so that straining was produced when the reflected tensile wave travelled back from the second bar. Albertini and Montagnani [5], Staab and Gilat [6] created a tensile wave directly by inducing the rapid fracture of a clamp at a point on a pre-stressed part of the incident bar.

In the case of metal sheets, the connection between the specimen and the bars is an important point. Clamping the specimen between jaws generally leads to an impedance mismatch, which at best gives only a reliable measurement of the force in the transmitter bar. Recently, Tanimura and Kuriu [7] presented a set-up based on the compressive SHPB where the axes of the bars were laterally shifted so that the relative displacement of the bar ends induced a traction state in the specimen. This specimen was connected to cylindrical supports which were not aligned with the axes of the bars. 
The set-up used here was a modified SHPB, where tension was produced in a very similar way to what occurs with the classical compression technique. Particular attention was paid to the force measurements at both specimen ends to ensure that the stress was accurately determined throughout the test.

\section{EXPERIMENTAL TECHNIQUES}

\subsection{General description}

Loading was applied to the incident bar in the form of a compressive wave and tension was induced in the specimen using a hat-shaped geometry (fig 1). This set-up made it possible to obtain a constant impedance while the waves were travelling along the bars on both sides of the specimen. A specific insert (the "pusher") was connected to the tip of the incident bar to load the bottom of the hat. Likewise, a second insert (the "support") was connected to the transmitter bar. Both connections between the inserts and the bars were implemented with aluminium rings screwed onto both the bar and the insert, which were especially designed so that their contribution to the impedance was negligible. As the incident and transmitter inserts could not have the same cross section for geometrical reasons (see fig. 1), the two bars did not have the same impedance.

One important feature of this system is that the region where the impedance change occurred between the bars and the specimen had the same thickness as the metal sheet. Consequently, the impedance change occurring at the bar-specimen connections was very similar to that observed in the case of a classical pure compression test, as illustrated in fig 2 . Fig 2 also summarises the dimensions and properties of the complete system, including the supports.

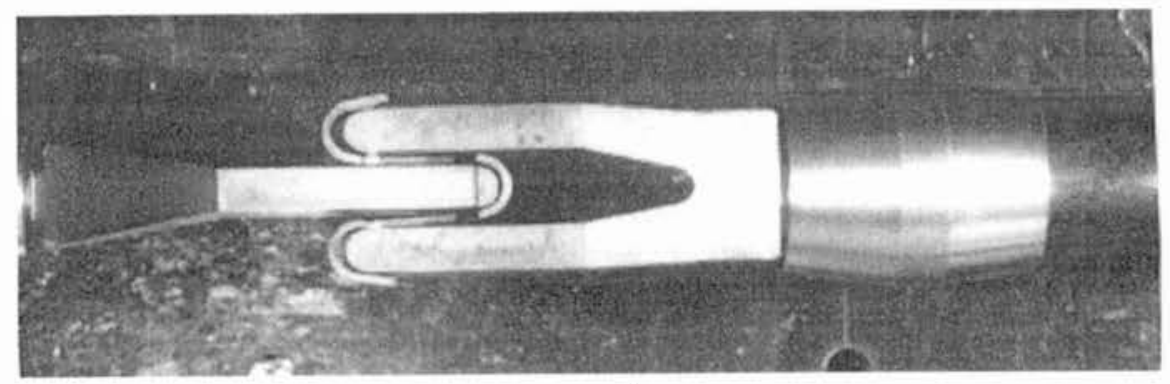

Figure 1. The hat specimen and special supports

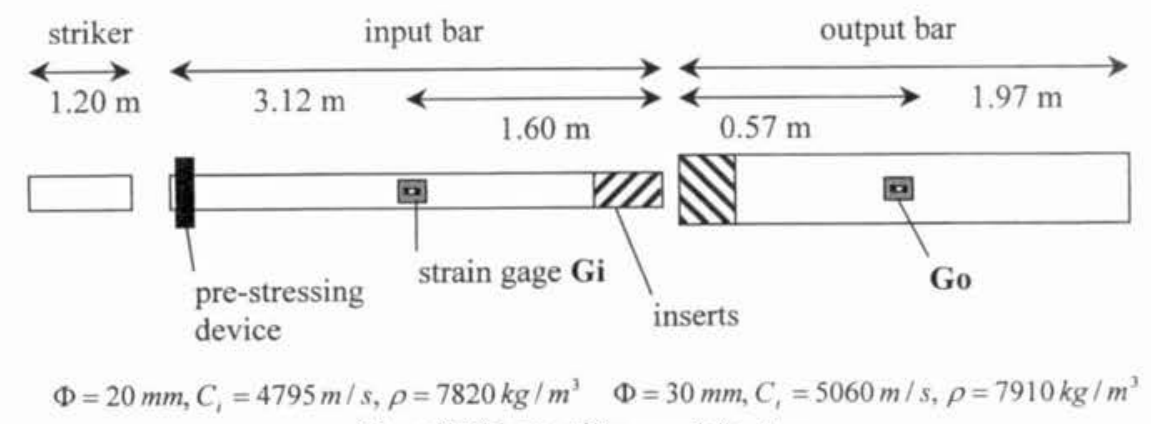

Figure 2. Scheme of the complete set-up. 
The specimen was connected by means of screws to each external face of the support. To ensure satisfactory contact conditions right from the onset of the dynamic loading, and promote the friction between the metal sheet and the tips of the support, the whole assembly was statically pre-stressed before the test. The value of the corresponding stress in the necked area of the specimen was deduced directly from the compressive strain measured in each bar (at gage stations $G i$ and $G o$, fig 2). This stress is a reasonable and significant fraction of the static yield stress characteristic of the metal sheet tested.

\subsection{Analysis and processing of gage measurements}

A complete data processing method was used on the waves. This method consisted in shifting the waves from the gage stations where they were first recorded to the bar ends. It included wave dispersion correction and an assisted delay setting based on the elastic transient response of the specimen, as described in [8]. With a classical SHPB set-up, where the bars have the same diameter and there is no initial pre-stressing of the specimen, the forces and speeds at both specimen ends are given by [8] :

$$
\begin{array}{ll}
F_{\text {input }}(t)=S_{B} E\left(\varepsilon_{i}(t)+\varepsilon_{r}(t)\right) & V_{\text {input }}(t)=-C_{0}\left(\varepsilon_{i}(t)-\varepsilon_{r}(t)\right) \\
F_{\text {output }}(t)=S_{B} E \varepsilon_{t}(t) & V_{\text {output }}(t)=-C_{0} \varepsilon_{t}(t)
\end{array}
$$

where $S_{B}, E$ and $C_{0}$ are the bar's cross-sectional area, Young's modulus and elastic wave velocity, respectively.

The strains used in these formulas are the virtual incident, reflected and transmitted strains that have been shifted to the bar ends using the data processing method mentioned above.

With the present set up, the appearance of both waves recorded differed from that of the waves observed in a classical SHPB. Figure 3 shows the signals recorded in a test performed with a short striker, to obtain a large delay between the incident and reflected signals. The main difference with a simple compression test was that the three waves no longer had the same vertical origin. In the case of the incident and transmitted waves, this was due to the differences between the diameters and Young's moduli of the two bars. In the case of the reflected wave, it was due to the null stress boundary conditions pertaining at the end of the incident bar after the impact (the input end of the incident bar escapes the static pre-stressing device).

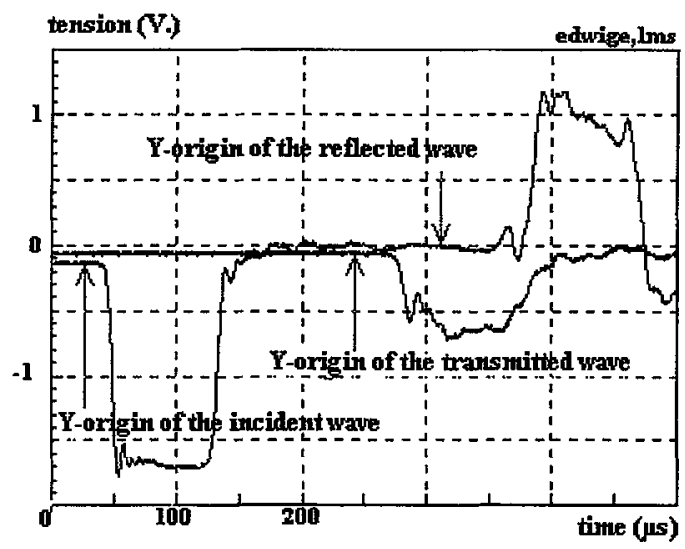

The classical formulas (1) have to be modified to take these differences into account. If the origins (on the $\mathrm{Y}$-axis) are taken to be at the constant baseline level of each signal before the onset of each wave (see fig. 3), those formulas become:

Figure 3. Basic recorded signals in pre-stressed bars. 


$$
\begin{array}{ll}
F_{\text {input }}(t)=S_{i} E_{i}\left(\varepsilon_{i}(t)+\varepsilon_{r}(t)\right)+F_{p s} & V_{\text {input }}(t)=-C_{i}\left(\varepsilon_{i}(t)-\varepsilon_{r}(t)\right) \\
F_{\text {output }}(t)=S_{t} E_{t} \varepsilon_{t}(t)+F_{p s} & V_{\text {output }}(t)=-C_{t} \varepsilon_{t}(t)
\end{array}
$$

where $S_{i}, E_{i}$ and $C_{i}$ are the incident bar's cross-sectional area, Young's modulus and elastic wave velocity, respectively, and $S_{t}, E_{t}$ and $C_{t}$ are the output bar's cross-sectional area, Young's modulus and elastic wave velocity, respectively.

As in the classical case, the strains used in these formulas were the virtual incident, reflected and transmitted strains that were shifted to the bar ends using the data processing method mentioned above.

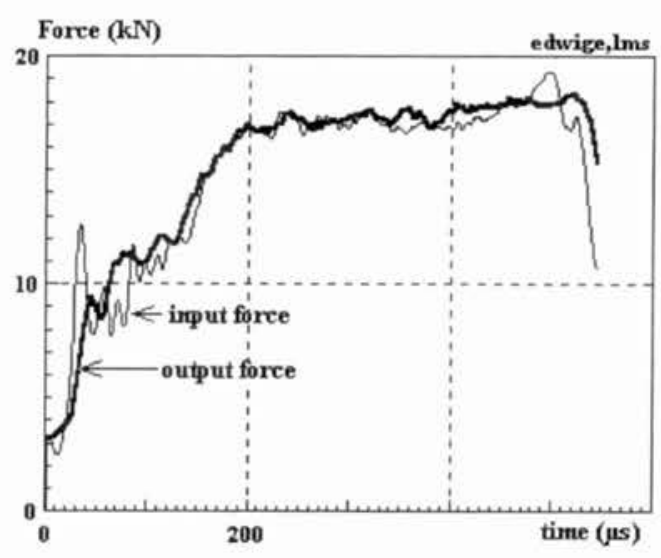

Figure 4. Equilibrium in the specimen: input and output forces.

It was checked that the input and output forces were equal before further processing the test data, to make sure that the specimen was in a homogeneous state of stress. An example of the force equilibrium is plotted in fig. 4 in the case of a $270 / \mathrm{s}$ test on mild steel.

\subsection{Specimen geometry}

Since the average traction force applied to the specimen was given, it was necessary in order to draw up a stress-strain plot to use a characteristic specimen length to calculate the strain, as the displacement measurements focused in the case of our set-up on the ends of the inserts. Harding and al. [3] , with their cylindrical specimen, carried out numerous static tests to obtain a strain-displacement relation that was non linear in the small strain range.

Using an explicit commercial code (LSDYNA3D) with various constitutive parameters, we investigated whether using the initial length of the necked area sufficed to be able to obtain the constitutive input relation. This simple analysis consisted in neglecting the strain in the wider parts of the specimen, focusing only on the necked area. Typical measured velocities were used as boundary conditions for $2 \mathrm{D}$ and $3 \mathrm{D}$ calculations. The force calculated was used instead of an experimental measurement to obtain a true stress-true strain plot. As shown in fig. 5, the simple geometry of our specimen appears to give reasonably good results when Ludwik and Johnson-Cook-like hardening laws are used. In addition, a significant improvement can be obtained using a modified geometry where the necked parts are split, with the same equivalent area, to produce a "comb-like" specimen. The effects of this operation were simulated with a specimen split into only two parts, as shown in fig. 5 .
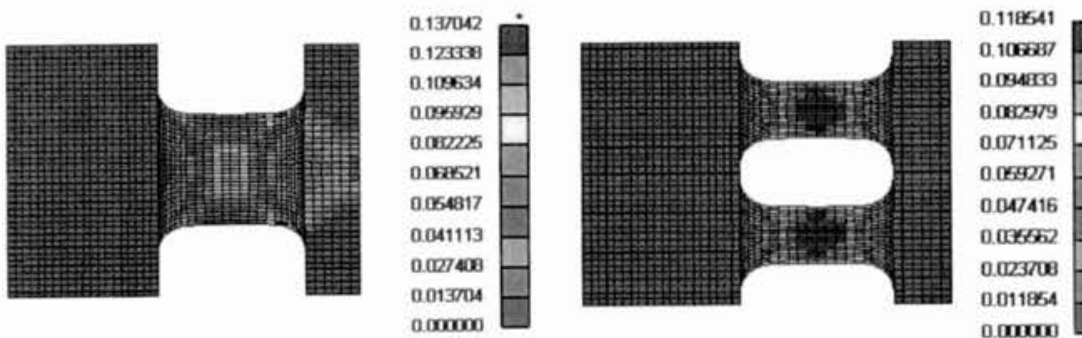


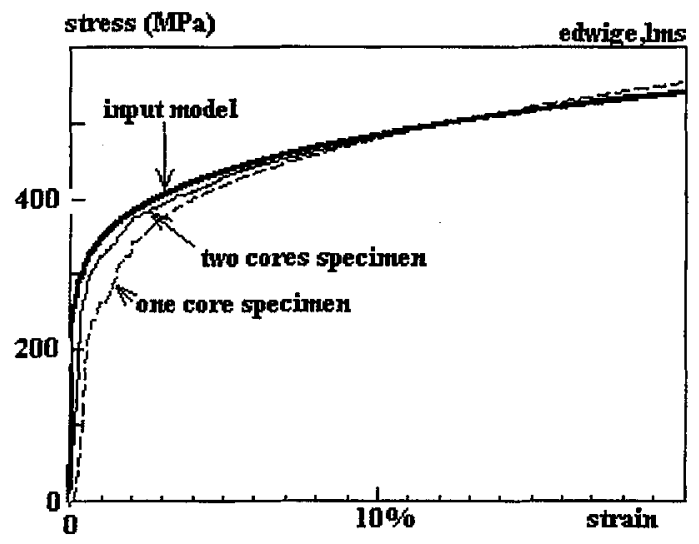

Figure 5. Influence of the "split" geometry of the specimen
The final shape of the initially flat machined specimen can be obtained by means of a folding technique, taking care that no plastification of the necked area can occur. The symmetry of the final specimen can be quite easily obtained provided that the folding device is accurately designed for each sheet thickness.

\section{RESULTS AND DISCUSSION}

Tests were performed with a mild-steel sheet that exhibits significant strain-rate effects when subjected to compression loading in the rolling direction. Specimens were cut at an angle of 90 degrees to the rolling direction. Fig. 6 shows the raw stress-strain curves obtained at four different strain-rates. Each test was performed twice and the results were fairly consistent. The evolution of the strain-rate during the test was naturally similar to that observed in compression tests.

This series did not exhibit a rate effect in the range of interest, which covers nearly a decade. Previous compression tests performed at authors laboratory $[9,10]$ on the same steel showed the occurrence of a $20 \%$ increase in the flow stress between the lowest and highest strain-rates reached here. The results obtained here under tension loading were unexpected, in view of the data available on mild-steel sheeting.

They should be compared with the results of similar tests performed on specimens cut in the rolling direction of the metal sheet.

The initial yield stress was found to be similar to the static value and lower than the yield stress recorded under compression loading, in line with the results obtained by Quik and al [1]. Since the strain hardening was found to be much greater under tension loading, the difference between the flow stresses disappeared at high strains.

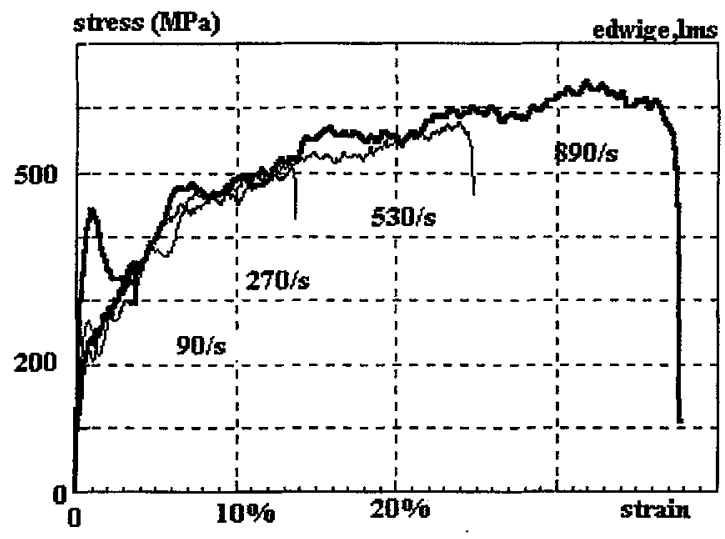

Figure 6. Stress-strain curves at various strain-rates.
The technique described here yields more satisfactory results than the dynamic tensile testing set-ups currently available for testing metal sheets. It can be used extensively on sheets of all thicknesses and specimens with a wide range of geometries, since the mode of connection with the bars does not distort the measuring signals. The results presented here are largely consistent with the known characteristics of mild steel. 


\section{CONCLUSION}

A modified SHPB device involving the use of a specially designed specimen was developed to evaluate the effects of the strain rate on the mechanical behaviour of metal sheets subjected to dynamic tension loading. The accuracy of the measurements thus obtained was confirmed by checking the balance between the input and output forces during the test and by performing dynamic numerical simulations of the specimen's response. In comparison with results obtained under compression loading, these preliminary results confirm that the loading sign (tension or compression) affects the stress-strain response and the effects of the strain-rate. The widely used rate-dependent isotropic plasticity model is not able to account for the results obtained under both tension and compression loading. FEM simulations, which are commonly used in the automotive industry, where metal sheets are used in car crash simulations, require the implementation of more accurate constitutive models taking these parameters into account.

A challenging issue for the next few years is to complete this model, including finding appropriate criteria that could be used instead of the Von Mises' criteria for simulating metallic shell structures under dynamic loading.

\section{Acknowledgements}

This work is supported by Peugeot-Citroën Automobiles. The authors would also like to thank Dynatis for the LSDYNA3D license.

\section{References}

[1] Lindholm U.S., (1964), Some experiments with the split Hopkinson pressure bar. J. Mech. Phys. Solids, 12, 317-335.

[2] Quik M., Labibes K., Albertini C., Valentin T., Magain P., "Dynamic mechanical properties of automotive thin sheet steel in tension, compression and shear ", J. Phys. IV France 7 (1997) C3-379384.

[3] Harding J., Wood E. O., Campbell J. D., "Tensile testing of materials at impact rates of strain" $J$. Mech. Eng. Sci. 2 (1960), 88-96.

[4] Nicholas T., "Tensile testing of materials at high rates of strain ", Experimental Mechanics, 21 (5) (1981), 177-185.

[5] Albertini C., Montagnani M., "Testing techniques based on the split Hopkinson Pressure Bar", in Mechanical Properties at High Rates of Strain, The Institute of Physics, London (1974).

[6] Staab G. H., Gilat A. "A direct-tension split Hopkinson bar for high strain-rate Testing", Experimental Mechanics, 48 (1991) 232-235.

[7] Tanimura S., Kuriu N. "Mechanical properties of sheet steel at high strain rates ", Proceedings of the $2^{\text {nd }}$ Materials and Processing Conference (M \&P'94, JSME) No. 940-36, 144-145.

[8] H.Zhao, G.Gary, On the use of SHPB technique to determine the dynamic behavior of the materials in the range of small strains, International Journal of Solids \& Structures. Vol. 33, pp.3363-3375, 1996.

[9] Zhao H., " A constitutive model for metals over a large range of strain rates. Identification for mildsteel and aluminium sheets ", Mat. Sci. Eng., A230 (1997), 95-99.

[10] Zhao H., Gary G., " The testing and behaviour modelling of sheet metals at strain rates from $10^{-4}$ to $10^{4} / \mathrm{s}$ ", Mat. Sci. Eng., A207 (1996), 46-50. 